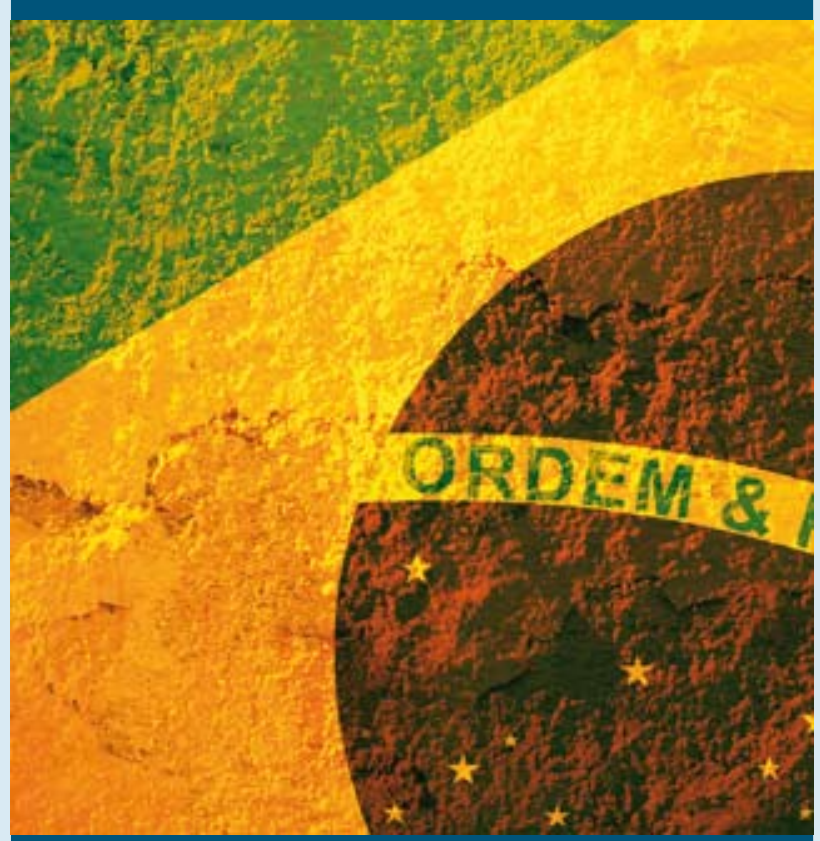

Manifestação do Concefet sobre os Institutos Federais de Educação, Ciência e Tecnologia 


\section{Apresentação}

O Conselho de Dirigentes dos Centros Federais de Educação - Concefet, neste documento, se manifesta em relação à proposta de criação dos Institutos Federais de Educação, Ciência e Tecnologia - IFET, cuja principal referência, no momento, é o Decreto no 6.095, de 24 de abril de 2007. Este documento é fruto dos debates, no âmbito do Concefet, que sucederam a apresentação da proposta de criação dos Institutos Federais dentre as medidas contidas no Plano de Desenvolvimento da Educação - PDE do segundo governo do presidente Luiz Inácio Lula da Silva e representa o sentimento dos diretores gerais de que a nova construção institucional pode melhor traduzir o significado da educação profissional e tecnológica enquanto modalidade potencializadora do indivíduo no desenvolvimento de sua capacidade de gerar conhecimento a partir de uma prática interativa com a realidade.

Os Institutos Federais podem se constituir em fundamentais espaços no âmbito das políticas que visam à construção de caminhos voltados para o desenvolvimento socioeconômico regional a partir de uma conduta articulada ao contexto produtivo do território onde está instalado, que significa relacionar o seu trabalho à vocação produtiva e demandas do seu lócus. Assim, a formação profissional, na qual se inclui a de professores, a difusão, popularização e democratização do conhecimento científico são itens constitutivos da identidade dos Institutos Federais. O Conselho de Dirigentes dos Centros Federais de Educação Tecnológica, por outro lado, ao assumir posição, o faz colocando em destaque a concepção de instituição que defende as condições objetivas necessárias para a sua materialização. 


\section{IFET - Construção da Identidade}

O termo instituto carrega vários significados: pode ser a designação de organizações de caráter educacional, acadêmico, cultural, artístico, profissional, esportivo, religioso e outros, ou ainda pode denotar expedientes regidos por normas, regulamentos, rituais (instituto do casamento, do pátrio poder etc.). O complemento federal explica a sua natureza pública e o seu vínculo enquanto mantido pelo Governo Federal. No entanto, é na educação, ciência e tecnologia que se revela o seu espaço de atuação, na função social a que está intrinsecamente vinculado, que é possível compreender melhor a sua identidade.

A proposta de criação dos Institutos Federais de Educação, Ciência e Tecnologia, segundo o Decreto no 6.095, de 24 de abril de 2007, tem endereço: a Rede Federal de Educação Tecnológica e os Centros Federais de Educação Tecnológica - Cefet. No que pese esta referência - traduzir a origem e conferir algum significado aos Institutos Federais -, ela é insuficiente para compreender a proposta na sua totalidade. Nesse sentido, é natural que se pergunte o porquê da proposição se o reconhecimento social dos Cefets faz destes um dos melhores exemplos brasileiros de experiência bem-sucedida enquanto instituição pública voltada para a qualificação profissional. Que singularidades há nos Institutos Federais que podem conferir a estas instituições a capacidade de tornar substantivo o seu papel?

\section{É na educação, ciência e} tecnologia que se revela o seu espaço de atuação.

\section{a) Contexto histórico}

A formação para o trabalho nas primeiras décadas do Brasil Republicano foi expediente largamente usado pela classe dirigente como meio de contenção do que ela considerava "desordem social", na verdade, sinais presentes em cenário dinâmico e em transição, moldado fortemente pelo processo de urbanização, com notável mobilização popular e classista em busca de melhores condições de vida e de trabalho ${ }^{1}$. O Estado brasileiro, em 23 de setembro de 1909, através do Decreto no 7.566, assinado pelo presidente Nilo Peçanha, justifica a criação de uma rede de Escolas de Aprendizes e Artífices, a partir da necessidade de prover os "desfavorecidos da fortuna", expressão contida no Decreto no 7.566/09, isto é, prover as classes proletárias de meios que garantissem a sua sobrevivência.

No final dos anos 1930, as Escolas de Aprendizes Artífices dão lugar os Liceus Industriais, mas esta mudança pouco altera os objetivos atribuídos àquelas, no entanto, é a partir de 1942 que surgem as Escolas Industriais e Técnicas, no lugar dos Liceus Industriais, com o objetivo de oferecer formação profissional em nível equivalente ao do secundário. A mudança das instituições federais está colocada no espaço de significativas mudanças na economia brasileira, que entre os anos de 1930 e 1945 altera definitivamente o seu eixo, deslocando-se da atividade agro-exportadora para a industrial. No ano de 1959, as Escolas Industriais e Técnicas são transformadas em autarquias e passam a ser denominadas Escolas Técnicas Federais. As instituições ganham autonomia didática e de gestão; com isso, intensificam a formação de técnicos, mão-de-obra indispensável diante da aceleração do processo de industrialização.

O período da Ditadura Militar é marcado por profundas mudanças na política de educação profissional, o que também se pode justificar pelo seu projeto de desenvolvimento. Assim é que, em 1971, a Lei de Diretrizes e Bases da Educação torna, de maneira com-

1. Apenas a título de ilustração: data de 1904 a chamada "Revolta da Vacina", movimento popular ocorrido na cidade do Rio de Janeiro, uma cidade com ruelas estreitas e sujas, cheia de cortiços, onde se amontoa a população pobre. A falta de saneamento básico e as condições de higiene fazem da cidade um foco de epidemias, principalmente febre amarela, varíola e peste.

A fundação da Confederação Operária Brasileira (COB), em 1906, por iniciativa de sindicatos do Rio de Janeiro, São Paulo, Bahia, Rio Grande do Sul e Pernambuco, foi um dos mais importantes marcos no processo de mobilização do operariado brasileiro.

Em 1907, ocorreu uma greve de pedreiros na cidade de São Paulo, engrossada por outras categorias, reivindicando a redução da jornada de trabalho, elevação de salário etc. 
pulsória, técnico-profissional todo currículo do segundo grau. Um novo paradigma se estabelece: formar técnicos sob o regime da urgência. Nesse tempo, as Escolas Técnicas Federais aumentam expressivamente o número de matrículas e implantam novos cursos técnicos. Em 1978, três Escolas Técnicas Federais (Paraná, Minas Gerais e Rio de Janeiro) são transformadas em Centros Federais de Educação Tecnológica. Esta mudança confere àquelas instituições mais uma atribuição: formar engenheiros de operação e tecnólogos, processo esse que se estende às outras instituições bem mais tarde.

Em 1996, a Lei de Diretrizes e Bases da Educação Nacional, no 9.394, é aprovada e, no ano seguinte, através do Decreto no 2.208, se dá a regulamentação dos artigos da nova LDB, que tratam especificamente da educação profissional. As mudanças alteram todo o processo para a qualificação de mão-de-obra. Em meio às transformações da educação profissional, retoma-se, em 1999, o processo de transformação das Escolas Técnicas Federais em Centros Federais de Educação Tecnológica (Cefets) iniciado em 1978.

Na esteira do projeto educacional, o governo brasileiro assina convênio com o Banco Interamericano de Desenvolvimento (BID) e cria o Programa de Expansão da Educação Profissional (Proep), braço financiador da reforma, o que concorreu, de certa forma, para acirrar os debates e impulsionar as escolas no sentido de ganharem identidade própria e assumir posição face à realidade do mundo produtivo e da sociedade. Os anos de 1990 mereceriam, pois, análise especial e criteriosa, uma vez que as escolas da rede procederam a uma movimentação sem precedente no que se refere à construção de suas propostas pedagógicas, tornando visível a opção que cada uma delas - na maturidade construída nas questões principalmente da educação/trabalho/tecnologia, numa verdadeira correlação de forças no que se refere a decisões que não emanavam de tudo que fora até então concebido como formação do homem e de seus direitos de cidadania.

A partir deste momento histórico, a reformulação curricular que se processou no interior dos Cefets eleva em escala de grandeza seu potencial para estar respondendo aos anseios da sociedade que concorrem significativamente para mudar a realidade da região onde atua, seja no ensino, na pesquisa ou na extensão. Esse processo de construção, situado e datado, sintonizado com o desenvolvimento do país numa concepção de escala que vai do regional ao global, referenda essas instituições na produção e democratização do conhecimento em todos os níveis e graus de ensino, mas tomando como fundamento precípuo a dimensão humana da formação, traduzida no sentido da emancipação.

\section{b) Desenvolvimento regional e interiorização da EPT}

No atual cenário, essa rede de escolas federais pode se ocupar de forma substantiva de um trabalho mais contributivo, intrinsecamente voltado para o desenvolvimento local e regional, apreendendo desenvolvimento local e regional como a melhoria do padrão de vida da população de uma região geograficamente delimitada, em grande parte fruto do maior dinamismo das atividades produtivas aí presentes; maior dinamismo como resultado de alterações fundamentais na estrutura da economia da região, em boa parte provocada pelo incremento de conhecimento, tecnologia e mãode-obra qualificada.

\section{c) Acolhimento de novos públicos}

A reestruturação organizativa da educação profissional e tecnológica deve ser realizada também em função das novas demandas colocadas pelo atual contexto histórico e regional. Nesse sentido, já se observam algumas necessidades educacionais oriundas das reivindicações das comunidades locais, movimentos sociais e setores produtivos, são elas: educação de jovens e adultos integrada à educação profissional, educação de pessoas portadoras de deficiência, formação continuada de técnicos, tecnólogos, bacharéis e licenciados, educação para a diversidade cultural (população do campo, indígena, quilombolas, ribeirinhos).

Considera-se, portanto, que os Institutos Federais de Educação, Ciência e Tecnologia deverão garantir a perenidade das ações, por meio das políticas públicas e de financiamento, que visem incorporar setores sociais que historicamente foram alijados dos processos de desenvolvimento e modernização do Brasil e viabilizar, desta forma, o pagamento da dívida social em relação a esse público. 


\section{d) Formação em novas áreas}

As sucessivas transformações por que vêm passando as instituições federais de educação profissional, notadamente os Cefets, incorporam novos requerimentos da sociedade e estes passam a atender novas demandas.

Até a década de 1980, a formação profissional limitava-se ao treinamento para a produção em série e padronizada. A partir de então, as novas formas de organização e gestão modificaram estruturalmente o mundo do trabalho. Um novo cenário econômico e produtivo se estabeleceu com o desenvolvimento e emprego de tecnologias complexas agregadas à produção e à prestação de serviços e pela crescente internacionalização das relações econômicas (Parecer CNE/CES no 436/2001).

Com a Lei no 8.711/93, que cria o Cefet/BA, a redação dada às finalidades dessa instituição inclui "o oferecimento de educação tecnológica" em substituição ao "ensino industrial" então em uso nos textos legais disciplinadores do funcionamento das escolas técnicas de origem industrial.

O novo escopo que então passou a ser delineado veio permitir o desenvolvimento do ensino profissional e tecnológico em diferentes setores do conhecimento para diferentes áreas do mundo do trabalho. Através da Resolução CNE/CEB no 04/99, ficam instituídas as diretrizes curriculares nacionais para a educação profissional de nível técnico, configurando um quadro com 20 áreas profissionais.

Adiante, em 2001, com a edição, pelo Conselho Nacional de Educação, do Parecer CNE/CES no 436, de 2 de abril de 2001, essa orientação passa a vigorar também para o ensino superior de tecnologia que adota as mesmas áreas para este nível de ensino.

\section{e) Formação de professores}

Além da formação nas diferentes áreas profissionais em níveis técnico e tecnológico, a legislação dispõe, ainda, sobre a formação de professores "ministrar cursos de licenciatura, bem como programas especiais de formação pedagógica, nas áreas científica e tecnológica" (Decreto no 5.224, artigo 4으, inciso VII).
A preocupação com a boa formação profissional não poderia estar dispersa da qualidade dos professores. A lógica da formação qualificada inclui formadores qualificados. Deriva daí a oferta de cursos de licenciatura e de programas especiais de formação pedagógica para professores da educação básica e profissional.

Essa ação atribuída ao Cefet completa um ciclo de objetivos institucionais em que sua atividade transita do particular para o universal e, nessa perspectiva, o Cefet ganha a condição de universidade stricto sensu, ou seja, a universidade do ensino profissional e tecnológico. A formação que o Cefet oferece não é universal porque cuida de todas as áreas do conhecimento, mas porque se desenvolve em todos os níveis, que vai desde a formação inicial e continuada até a pós-graduação.

\section{f) Verticalização do ensino e acesso ao ensino superior}

Os Institutos Federais apresentam uma característica ímpar dentre as instituições educacionais: é a flexibilidade curricular de verticalização da formação do estudante a partir da educação de nível médio integrada à educação profissional de nível técnico, e essa articulada com a graduação tecnológica, com as especializações e com a pós-graduação. O itinerário percorrido pelo formando da educação básica até a educação superior dentro dessas instituições, numa mesma área de conhecimento científico e tecnológi$\mathrm{Co}$, trata-se de um modelo de qualidade educacional já aprovado no país, pelos resultados de destaque obtidos pelos egressos dos Institutos Federais.

Vale ressaltar outra questão muito importante da verticalização. Trata-se da otimização da infra-estrutura da escola, no tocante às instalações físicas de salas de aula, laboratórios, equipamentos, salas especiais e outros ambientes de apoio didático-administrativo, bem como quanto aos recursos de pessoal técnico-administrativo e de docentes, uma vez que atendem, simultaneamente, de forma articulada, aos níveis técnico e superior da educação profissional, bem como à pósgraduação. Essa condição tem dado oportunidade aos professores, entre outras coisas, associar teoria e prática em qualquer dos níveis de ensino, permitindo-lhes uma visão mais ampla da educação e de suas relações com o mundo do trabalho e com a sociedade em geral. 


\section{g) Pesquisa, inovação tecnológica e democratização do conhecimento científico}

Nas sociedades modernas, a institucionalização das áreas de pesquisa científica, tecnológica e de inovação fortalece o campo de atuação do Estado como agente de indução e mediação junto ao setor produtivo. Os Institutos Federais propõem um desenho institucional nesse campo que apresenta contribuições significativas para a educação brasileira, tanto básica como superior, uma vez que entende fundamental que se assuma a pesquisa como um princípio educativo irrenunciável em todos os níveis educacionais com vistas à construção da unidade ensino-pesquisa-aprendizagem e, em conseqüência, da formação da autonomia intelectual dos formandos em todos os níveis educacionais.

A democratização dos conhecimentos exige assumir a pesquisa como princípio educativo em todos os níveis, visando acompanhar o acelerado ritmo das descobertas e avanços do mundo científico e inovações tecnológicas que coloca à disposição dos setores produtivos novos materiais, sistemas informatizados de produção e novos processos e técnicas de gestão. Através dos eixos temáticos dos conteúdos curriculares, deve ser incentivado o trabalho de pesquisa e a investigação científica, promovendo a divulgação de conhecimentos culturais, científicos e tecnológicos que constituem o patrimônio da humanidade. Articuladas com essas atividades, surgem, naturalmente, as ações de extensão, garantindo a qualidade e legitimidade do trabalho acadêmico, a liberdade intelectual e a produção e divulgação de resultados, favorecendo a constituição de parcerias e acordos de intercâmbios com entidades, empresas e centros de excelência do país e do exterior, favorecendo a transferência de tecnologias sociais.

O Concefet afirma ainda que esta posição dos dirigentes dos Cefets se vincula estritamente aos seguintes pontos:

1. adoção de um processo de implantação disposto em lei única;

2. inclusão dos Institutos Federais de Educação, Ciência e Tecnologia - IFET entre as entidades que constituem o Sistema Federal de Educação Superior, com prerrogativas equivalentes às da universidade, caracterizadas em toda legislação que trata desse nível de ensino;

3. a implementação, pelo Ministério da Educação, de política de apoio que garanta iguais condições (recursos humanos e materiais) aos atuais Cefets e à ETF/Palmas, para sua transformação em Instituto Federal;

4. a adoção de providências para implantação de um Plano de Cargos e Carreira de Professores da Educação Tecnológica - PCCPET, consoante com as prerrogativas da nova instituição, e que assegure os direitos hoje consignados em lei aos atuais quadros do ensino do $1 \underline{0}$ e $2^{\underline{o}}$ graus e do ensino superior dessas instituições;

5. garantia do processo de escolha do dirigente máximo dos Institutos Federais a partir de eleição direta, de acordo com o que dispõe a legislação em vigor sobre o processo de escolha dos diretores gerais dos Cefets;

6. garantia de que as prerrogativas e objetivos dos Institutos Federais tenham como base a preservação das conquistas históricas da rede de Cefet e ETF/Palmas, a fim de reafirmar seu trabalho educativo em favor do desenvolvimento da nação brasileira, entre os quais se incluem: a natureza pública das instituições e a coexistência do ensino técnico, superior (graduação e pós-graduação), pesquisa e extensão;

7. a criação, em lei, de um Fundo de Financiamento e Desenvolvimento da Educação Profissional e Tecnológica, a fim de garantir de modo definitivo à educação profissional e tecnológica o seu caráter estratégico e, ao mesmo tempo, inseri-la no rol das políticas de Estado;

8. preocupação com a afirmação da rede federal (enquanto de formação profissional e tecnológica) com os princípios balizadores de sua atuação, o que a faz reconhecida em todo o território nacional; e

9. a ênfase na educação profissional e tecnológica, pesquisa e extensão, com o fortalecimento da educação técnica de nível médio, integrada à educação básica. 


\title{
Proposta de Projeto de Lei
}

\author{
PROPOSTA DE MINUTA DE ANTEPROJETO DE LEI
}

Institui a Rede Federal de Educação Profissional, Científica e Tecnológica e os Institutos Federais de Educação, Ciência e Tecnologia e dá outras providências.

Art. 1으 - Fica instituída, no âmbito do Sistema Federal de Educação, a Rede Federal de Educação Profissional, Científica e Tecnológica, constituída pelos Institutos Federais de Educação, Ciência e Tecnologia - IFET, Universidades Federais Tecnológicas, Centros Federais de Educação Tecnológica e Escolas Técnicas Federais, vinculados ao Ministério da Educação.

§ $1 \underline{0}$ - Os Institutos Federais são instituições de educação superior, básica e profissional, pluricurricular e multicampi, com atuação em diferentes modalidades de ensino, com base na conjugação de conhecimentos técnicos e tecnológicos às suas práticas pedagógicas, nos termos desta Lei.

$\S 2^{\mathrm{o}}$ - Para efeito da incidência das disposições que regem a regulação, avaliação e supervisão das instituições e dos cursos da educação superior, os Institutos Federais são equiparados às universidades federais.

$\S 3^{o}$ - Os Institutos Federais terão autonomia, nos limites de sua área de atuação territorial, para criar e extinguir cursos e registrar diplomas dos cursos por ele oferecidos, mediante autorização do seu Conselho Superior.

Art. $2^{\underline{O}}-\mathrm{A}$ administração dos Institutos Federais terá como órgãos superiores o Colégio de Dirigentes e o Conselho Superior.

$\S 1^{0}$ - As presidências do Colégio de Dirigentes e do Conselho Superior serão exercidas pelo Reitor do Instituto Federal.

$\S 2^{\mathrm{o}}$ - O Colégio de Dirigentes, de caráter consultivo, será composto pelo Reitor, pelo Vice-Reitor, pelos Pró-Reitores e pelos Diretores-Gerais de cada campus que integra o Instituto Federal.

$\S 30$ - O Conselho Superior, de caráter consultivo e deliberativo, será composto por representantes dos docentes, dos estudantes, dos técnico-administrativos, dos egressos da instituição, da sociedade civil, do Ministério da Educação e do Colégio de Dirigentes do Instituto Federal.

$\S 4$ o - O estatuto do Instituto Federal disporá sobre a estruturação, as competências e as normas de funcionamento do Colégio de Dirigentes e do Conselho Superior.

Art. 3o - Fica criado, em cada unidade da Federação, um Fórum de Educação Profissional, Científica e Tecnológica com o objetivo de promover a articulação, a indução e a integração das políticas federais de educação profissional, ciência e tecnologia aos sistemas educacionais públicos e privados. 
§ 1으 - Compõem o Fórum definido nos termos do artigo 3o: os Reitores dos Institutos Federais inseridos na respectiva unidade da Federação; um representante da secretaria estadual de educação; dois representantes do Sistema S; um representante da secretaria estadual fomentadora do desenvolvimento, ciência e tecnologia; um representante patronal e um representante dos trabalhadores de cada uma das federações dos segmentos produtivos: agricultura, indústria e comércio; e seis representantes da sociedade civil, a serem definidos no respectivo regimento.

$\S 2 \mathrm{o}-$ O Fórum de que trata este artigo será presidido por um dos reitores dos Institutos Federais que o compõem, escolhido entre seus pares.

§ 3ํ- Caberá ao Ministério da Educação homologar o plano estratégico de gestão, aprovar o regimento e supervisionar o funcionamento de cada Fórum de Educação Profissional, Científica e Tecnológica criado nos termos deste artigo.

Art. 4으- - Os Institutos Federais têm por finalidades e características:

I - ofertar educação profissional e tecnológica, em todos os seus níveis e modalidades, formando e qualificando cidadãos com vistas à atuação profissional nos diversos setores da economia, com ênfase no desenvolvimento socioeconômico local, regional e nacional;

II - desenvolver a educação profissional e tecnológica, como processo educativo e investigativo de geração e adaptação de soluções técnicas e tecnológicas às demandas sociais e peculiaridades regionais;

III - promover a integração e a verticalização da educação básica/educação profissional e educação superior, otimizando a infra-estrutura física, os quadros de pessoal docente, técnico-administrativo e de gestão;

IV - orientar sua oferta formativa em benefício da consolidação e fortalecimento dos arranjos produtivos, sociais e culturais locais, identificados com base no mapeamento das potencialidades de desenvolvimento socioeconômico e cultural no âmbito de atuação do Instituto Federal;

$\mathrm{V}$ - buscar, constantemente, o aperfeiçoamento do ensino das ciências naturais, humanas e das linguagens, estimulando o desenvolvimento do espírito crítico, voltado à investigação científica e tecnológica;

$\mathrm{VI}$ - interagir com os sistemas públicos de ensino com vistas ao aperfeiçoamento do ensino das ciências naturais, humanas e das linguagens nas instituições públicas;

VII - desenvolver programas de extensão e de divulgação científica e tecnológica;

VIII - realizar e estimular a pesquisa, a produção cultural, o empreendedorismo, o cooperativismo e o desenvolvimento científico e tecnológico;

IX - promover a produção, o desenvolvimento e a transferência de tecnologias sociais;

$X$ - promover a produção, o desenvolvimento social e a preservação do meio ambiente.

Art. 5을 - Observadas as finalidades e características definidas no artigo 4으, são objetivos dos Institutos Federais: 
I - ministrar educação profissional técnica de nível médio, prioritariamente na forma de cursos integrados, para os concluintes do ensino fundamental e para o público da educação de jovens e adultos;

II - ministrar cursos de formação inicial e continuada de trabalhadores, objetivando a capacitação, o aperfeiçoamento, a especialização e a atualização de profissionais, em todos os níveis de escolaridade, nas áreas da educação profissional e tecnológica;

III - realizar pesquisas, na perspectiva da promoção do desenvolvimento científico, tecnológico e social;

IV - desenvolver atividades de extensão de acordo com os princípios e finalidades da educação profissional e tecnológica, em articulação com o mundo do trabalho e os segmentos sociais e com ênfase na produção, desenvolvimento e difusão de conhecimentos científicos e tecnológicos;

$\mathrm{V}$ - estimular e apoiar processos educativos que levem à geração de trabalho e renda, emancipação do cidadão na perspectiva do desenvolvimento socioeconômico local e regional;

VI - ministrar em nível de educação superior:

a) cursos superiores de tecnologia visando à formação de profissionais para os diferentes setores da economia;

b) cursos de licenciatura, bem como programas especiais de formação pedagógica, com vistas à formação de professores para a educação básica e para a educação profissional;

c) cursos de bacharelado e engenharia, visando à formação de profissionais para os diferentes setores da economia e áreas do conhecimento;

d) cursos de pós-graduação lato sensu, visando à formação de especialistas nas diferentes áreas do conhecimento;

e) cursos de pós-graduação stricto sensu de mestrado e doutorado, que contribuam para promover o estabelecimento de bases sólidas em educação, ciência e tecnologia.

Art. $6^{\mathbf{Q}}$ - No desenvolvimento da sua ação acadêmica, o Instituto Federal, em cada exercício, deverá garantir o mínimo de 50\% (cinqüenta por cento) de suas vagas para atender aos objetivos definidos nos incisos I e II do artigo 3o e o mínimo de $20 \%$ das vagas da educação superior para atender ao previsto na alínea b do inciso VI do artigo 5 ㅇ․

Parágrafo único. Nas regiões em que as demandas sociais pela formação em nível superior justificarem, o colegiado superior do Instituto Federal poderá autorizar o ajuste da oferta deste nível de ensino, sem prejuízo do índice definido neste artigo, para atender aos objetivos definidos nos incisos I e II do artigo 5‥

Art. 7으 - Os Institutos Federais de Educação, Ciência e Tecnologia terão como órgão executivo a Reitoria, composta de um Reitor, um Vice-Reitor e 10 (dez) Pró-Reitores.

Art. 8o - Os Reitores serão nomeados pelo Presidente da República, para mandato de quatro anos, permitida uma recondução, mediante eleição direta pela comunidade escolar, observando-se os pesos de dois terços para a manifestação dos servidores e de um terço para a manifestação do corpo discente. 
$\S 1$ o - Poderão candidatar-se aos cargos de Reitor os docentes pertencentes ao quadro de pessoal ativo permanente do Instituto Federal, desde que possuam o mínimo de dez anos de efetivo exercício na instituição e que atendam a, pelo menos, um dos seguintes requisitos:

I - possuir título de doutor;

II - estar posicionado na última classe da respectiva carreira docente.

$\S 3$ - - O mandato de Reitor extingue-se pelo decurso do prazo, ou, antes desse prazo, pela aposentadoria, voluntária ou compulsória, pela renúncia e pela destituição ou vacância do cargo.

$\S 4$ o - O Vice-Reitor e os Pró-Reitores são nomeados pelo Reitor do Instituto Federal, nos termos da legislação aplicável à nomeação de cargos de direção.

Art. 9o - Cada Instituto Federal é organizado em estrutura multicampi, com proposta orçamentária anual identificada para cada campus e a Reitoria, exceto no que diz respeito a pessoal, encargos sociais e benefícios aos servidores.

Parágrafo único. A Reitoria, como órgão de administração central, será instalada preferencialmente integrada ao campus do Instituto Federal melhor estruturado para atender aos objetivos institucionais.

Art. 10 - Os campi serão dirigidos por Diretores-Gerais, nomeados pelo Reitor, para mandato de quatro anos, permitida uma recondução, após processo de consulta à comunidade do respectivo campus, nos termos estabelecidos pelo estatuto do Instituto Federal.

$\S 1^{\mathrm{o}}$ - Poderão candidatar-se ao cargo de Diretor-Geral do campus, os servidores pertencentes ao seu quadro de pessoal ativo permanente, desde que possuam o mínimo de cinco anos de efetivo exercício no Instituto Federal e que atendam a pelo menos um dos seguintes requisitos:

I - ser docente do respectivo campus, com no mínimo dois anos de exercício em cargo de gestão no Instituto Federal;

II - ser técnico-administrativo do quadro de nível superior, com no mínimo dois anos de exercício em cargo de gestão no Instituto Federal.

$\S 2$ - Nos campi em processo de implantação, os cargos de Diretores-Gerais serão providos em caráter pro tempore, por designação do Reitor do Instituto Federal, até que seja possível identificar condições que atendam aos requisitos previstos no $\S 1^{0}$ deste artigo.

Art. 11 - O Poder Executivo encaminhará ao Congresso Nacional, no prazo máximo de cento e oitenta dias, contados a partir da publicação desta Lei, Projeto de Lei instituindo novo plano de carreira do magistério que contemple os docentes dos Institutos Federais.

Art. 12 - Os Centros Federais de Educação Tecnológica relacionados no Anexo I desta Lei ficam transformados em Institutos Federais de Educação, Ciência e Tecnologia.

$\S 1$ o - Os campi que constituem o Instituto Federal estão detalhados no Anexo I. 
$\S 2$ o - Os atuais Diretores-Gerais dos Centros Federais de Educação Tecnológica transformados em Institutos Federais nos termos desta Lei exercerão até o final os mandatos em curso e, em caráter pro tempore, a função de Reitor, com a incumbência de promover, no prazo máximo de cento e oitenta dias, a elaboração e encaminhamento ao Ministério da Educação do estatuto do Instituto Federal.

Art. 13 - As autarquias federais relacionadas no Anexo II desta Lei poderão ser transformadas em Institutos Federais de Educação, Ciência e Tecnologia, mediante decreto específico, após aprovação de projeto institucional que atenda aos critérios de desempenho e condições estruturais, administrativas e pedagógicas, a serem estabelecidos pelo Ministério da Educação.

Art. 14 - A criação de novos Institutos Federais de Educação, Ciência e Tecnologia - IFET, bem como a expansão da Rede Federal de Educação Profissional, Ciência e Tecnologia, obedecerá ao modelo e às diretrizes definidas nesta Lei e dependerá de parâmetros e normas a serem regulamentados pelo Ministério da Educação.

Art. 15 - Para a implantação dos Institutos Federais ficam criados, no âmbito do Ministério da Educação, os cargos técnico-administrativos e de professor, conforme disposto no Anexo III desta Lei.

Parágrafo único. Caberá ao Ministério da Educação definir a distribuição dos cargos entre os Institutos Federais de que trata esta Lei, atendido o disposto no Anexo III.

Art. 16 - Ficam criados, no âmbito do Ministério da Educação, os cargos de direção e funções gratificadas destinados aos Institutos Federais, atendido o disposto no Anexo IV.

Art. 17 - O provimento dos cargos e funções criados por esta Lei fica condicionado à comprovação da existência de prévia dotação orçamentária para atender às projeções de despesa de pessoal e aos acréscimos dela decorrentes, assim como à existência de autorização específica na Lei de Diretrizes Orçamentárias, conforme determina o parágrafo 1ํㅡㅁ do artigo 169 da Constituição Federal.

Art. 18 - Fica revogada a legislação em desacordo com esta lei. 
Por sua trajetória histórica, essas instituições possuem uma identidade com as classes menos favorecidas e com um trabalho no sentido da emancipação.

\section{Conclusão}

A criação dos Institutos Federais de Educação, Ciência e Tecnologia, no bojo do Plano de Expansão da Rede Federal de Educação Profissional e Tecnológica, representa o referendo do governo no sentido de colocar com maior destaque a educação tecnológica no seio da sociedade como instrumento vigoroso no trabalho de construção, resgate de cidadania e transformação social. A autonomia que lhe é reafirmada e ampliada poderia soar contraditória quando conjugada com o traçado de seu horizonte de atuação não fosse a decisão já firmada por essas instituições como sua identidade por toda a trajetória de um século de trabalho. Os Institutos Federais de Educação, Ciência e Tecnologia ganham um espaço exponencial de atuação visceralmente vinculado a um projeto de país que, na diversidade, na multiplicidade que lhe é peculiar, define seu traçado.

Assim, a responsabilidade que toma para si no universo da educação na sociedade brasileira, ao definir como meta central o desenvolvimento humano, intrinsecamente vinculado a uma proposta de trabalho enraizada com a realidade, a Rede Federal de Educação Tecnológica traz para dentro de seu lócus o compromisso com uma população diversificada, em diferentes estágios de formação, com desafios de vida cada vez mais complexos, cidadãos que alimentam expectativas bastante promissoras de vida. Cabe ressaltar, no entanto, que, por sua trajetória histórica, essas instituições possuem uma identidade com as classes menos favorecidas e com um trabalho no sentido da emancipação. É neste sentido que desenha diferentes traçados de formação, cria caminhos libertadores também para aqueles que não puderam realizar uma trajetória de formação acadêmica, como seria de seu direito, e se afastaram dos bancos escolares e voltam em fase adulta, com sua bagagem de vida para resgatar sua cidadania; constrói caminhos alternativos para grupos organizados que almejam, de forma empreendedora, em parceria com comunidades organizadas, resgatando o sentimento de pertencimento à sociedade; atinge comunidades antes não imaginadas quando dialoga com municípios das regiões próximas, construindo com as instâncias do poder público possibilidades diversas no sentido do acesso ao conhecimento, à produção científica e às novas tecnologias; dialoga com o setor produtivo no sentido de atender às exigências na formação do cidadão produtivo. Na outra ponta, por se depararem com a ampliação deste naipe de possibilidades, não seria possível um tratamento acadêmico de qualidade ao trabalho sem estruturar de forma bastante delineada a pesquisa e a extensão, com comprometimento com a inovação tecnológica, como forma de garantir a propriedade de suas ações e elevar significativamente o nível do trabalho na produção e democratização do conhecimento, daí sua decisão em ampliar ações nessas duas vertentes, construindo o tripé que constitui um espaço universitário.

É importante ressaltar que da diversidade de seu público, do mosaico que constitui a diversidade da sociedade brasileira, essas instituições extraem elementos para construir seu projeto de educação profissional e tecnológica, sua identidade, pois reconhecem que congregam, em tom de esperança, vozes que lutam por um mundo mais digno e ético. 